\title{
Design da informação e o registro de uma técnica têxtil: A renda renascença
}

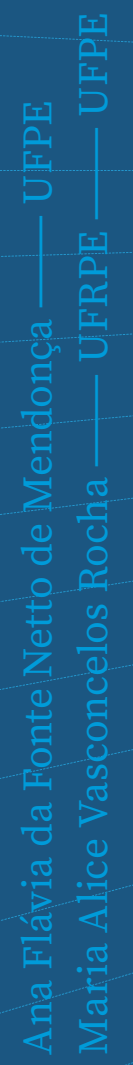




\section{INTRODUÇÃO}

O objetivo deste trabalho é representar graficamente o passo a passo da construção têxtil dos pontos da renda Renascença produzida, na atualidade, no município de Poção, Agreste de Pernambuco. Na jornada rumo à representação imagética destes movimentos de agulha e linha, para que este conhecimento artesanal fique registrado e não se perca com o passar do tempo e com futuras mudanças econômicas e sociais, buscou-se conhecer, também, a história deste trabalho manual. Para o desenvolvimento deste estudo, tomou-se como premissa a adoção do olhar promovido pelo campo do Design da Informação, em especial a atividade de representação da ação.

Conhecimento artesanal têxtil secular, a renda Renascença chegou ao Agreste de 
Pernambuco no início do século XX e encontrou amplo espaço para desenvolvimento. Integrante do grupo das rendas feitas com agulha, a estrutura para a execução da renda Renascença se dá a partir de um desenho-base realizado em papel manteiga e fixado a um papel mais grosso ou a um plástico para dar mais firmeza à estrutura. Em seguida, uma espécie de fita de algodão com bordas dentadas, denominada Lacê, é posicionada sobre o papel e alinhavada seguindo o desenho-base. O lacê é uma fita que atua como armação para o feitio da renda, sustentando os pontos. Utilizando agulha e linha, se faz o preenchimento dos espaços vazios entre os lacês com os diferentes tipos de pontos. Finalizada a trama, o alinhavo é desfeito e a renda é solta do papel. Inicia-se a etapa de acabamento, com o reforço da junção, pelo avesso, entre as áreas de recortes do lacê. Em alguns casos, a renda ainda é tingida, lavada, engomada e passada a ferro antes de ser levada aos pontos de venda. É um trabatho artesanal que se caracteriza pela delicadeza e miudeza dos pontos e que consome bastante tempo para ser realizado.

O tema foi escolhido pela importância de documentar a produção da renda Renascença feita em Pernambuco, visto que o desempenho do trabalho artesanal nesta região enfrenta dificuldades e pode se extinguir com o passar do tempo e com as mudanças de hábito de consumo das novas gerações. No Brasil, foram encontrados dois livros publicados que abordam especificamente a Renda Renascença, obras de Nóbrega (2005) e Queiroga (2013). Também há duas publicações impressas sobre o tema: uma em forma de almanaque, elaborado com apoio do Fundo Internacional de Desenvolvimento Agrícola, do Instituto Interamericano de Cooperação para a 
Agricultura e da Agência Espanhola de Cooperação Internacional (2017); outra em forma de catálogo, incentivado pelo Governo de Pernambuco, através do Funcultura (2016). Também há alguns artigos e ensaios de abordagem mais comercial ou acadêmica, porém, não foi encontrada nenhuma bibliografia sobre como fazer a renda Renascença produzida no Brasil, ou seja, nenhum registro do passo a passo deste artesanato têxtil.

Embora seja comercializada em lojas de souvenir em todo Nordeste e existam pontos de venda também em outras regiões do país, só há um único polo de produção da Renda Renascença no Brasil, que abrange o Agreste de Pernambuco e o Cariri da Paraíba, áreas vizinhas, divididas apenas por uma fronteira política. Todo o conhecimento da Renascença foi passado até hoje, na região, unicamente pela transmissão oral. Assim, o estudo teve por objetivo geral registrar a importância da renda Renascença pernambucana por meio da representação esquemática dos principais pontos, com o intuito de que esta técnica têxtil não se perca com o passar do tempo. A partir dos estudos de alguns teóricos do Design da Informação, foi criada uma maneira de representar os movimentos de linhas e agulhas para a preservação da memória da construção têxtil de dezesseis pontos significativos na produção da renda Renascença pernambucana. 


\section{MÉTODOS E TÉCNICAS}

A pesquisa empregou o método indutivo de abordagem, que parte da constatação de dados particulares para atingir uma verdade geral. Segundo Marconi e Lakatos (2003, p.87), a indução realiza-se em três etapas: observação dos fenômenos, descoberta da relação entre eles e generalização da relação, "nesta última etapa generalizamos a relação encontrada na precedente, entre os fenômenos e fatos semelhantes, muitos dos quais ainda não observamos (e muitos inclusive inobserváveis)". As etapas da pesquisa envolvem: coletar os dados de como executar cada ponto, desenhar manualmente o passo a passo da construção de cada ponto, conferir a eficácia do desenho após um intervalo de contato com o material e, por último, passar o desenho manual para o computadorizado, através do Adobe Illustrator. 
Figura 01.

Famílias de pontos da renda Renascença.

Fonte: Elaborado

pela autora.

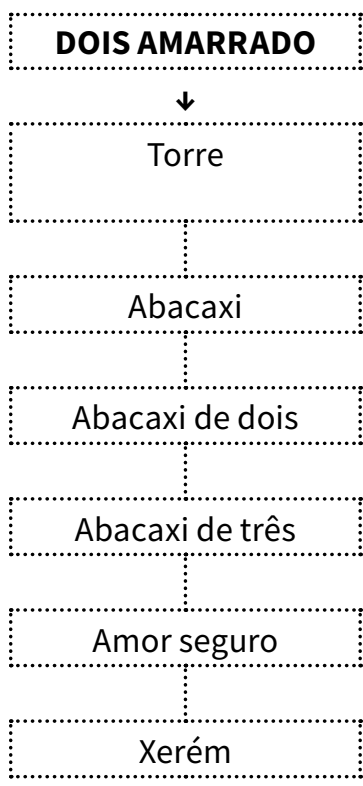

Para que o registro gráfico se mostrasse preciso, foi necessária a aprendizagem dos pontos pela pesquisadora, uma vez que, logo no início das tentativas de desenho apenas por observação não-participante, percebeu-se que a rapidez dos rendeiros, acostumados ao trabalho artesanal há décadas, desafiava o registro com lápis e borracha das etapas de construção dos pontos. Segundo Marconi e Lakatos (2003), uma das limitações da técnica de observação é justamente essa: a rápida duração dos acontecimentos pode tornar difícil a coleta de dados. Com o intuito de controlar a velocidade, a pesquisadora solicitou um "rolo" (almofada) de Renascença para si, a fim de treinar a construção dos pontos enquanto observava a execução pelos rendeiros.

"Dois amarrado", "Sianinha”, "Pipoca”, "Malha”, "Torre”, "Traça”, "Xerém”, "Abacaxi”, "Abacaxi de dois", "Sianinha de laço", "Aranha tecida" e "Ponto São Paulo" - estes são os pontos mais citados na pesquisa prévia, de caráter exploratório, com sessenta e nove rendeiras da região. Inicialmente, a aprendizagem seguiu esta ordem, porém, logo foi notada a existência de "famílias de pontos": o conhecimento de um ponto levava ao ensino de outro "parecido" e assim por diante. No final da pesquisa, foram desenhados dezesseis pontos que podem ser agrupados em quatro "famílias", como pode-se observar na Figura 01, abaixo:
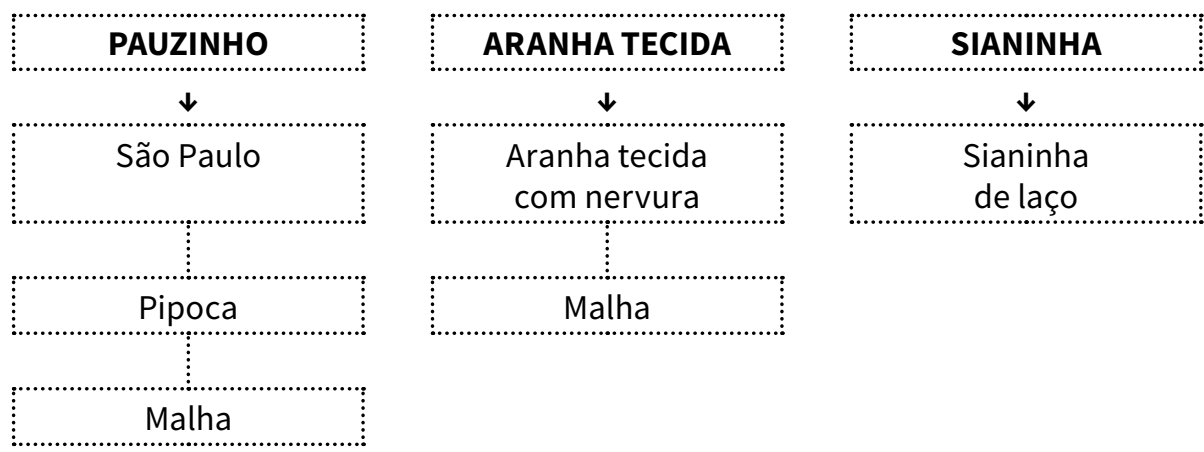
Após a compreensão da feitura de cada um dos pontos, foi possível fazer estas associações de construções têxteis, tornando mais didático o processo de ensino/aprendizagem da Renascença por desenhos esquemáticos. Muita borracha foi gasta até os desenhos começarem a ganhar corpo. Abaixo, na Figura 02, é possível observar um esboço dos primeiros passos do ponto "Malha":

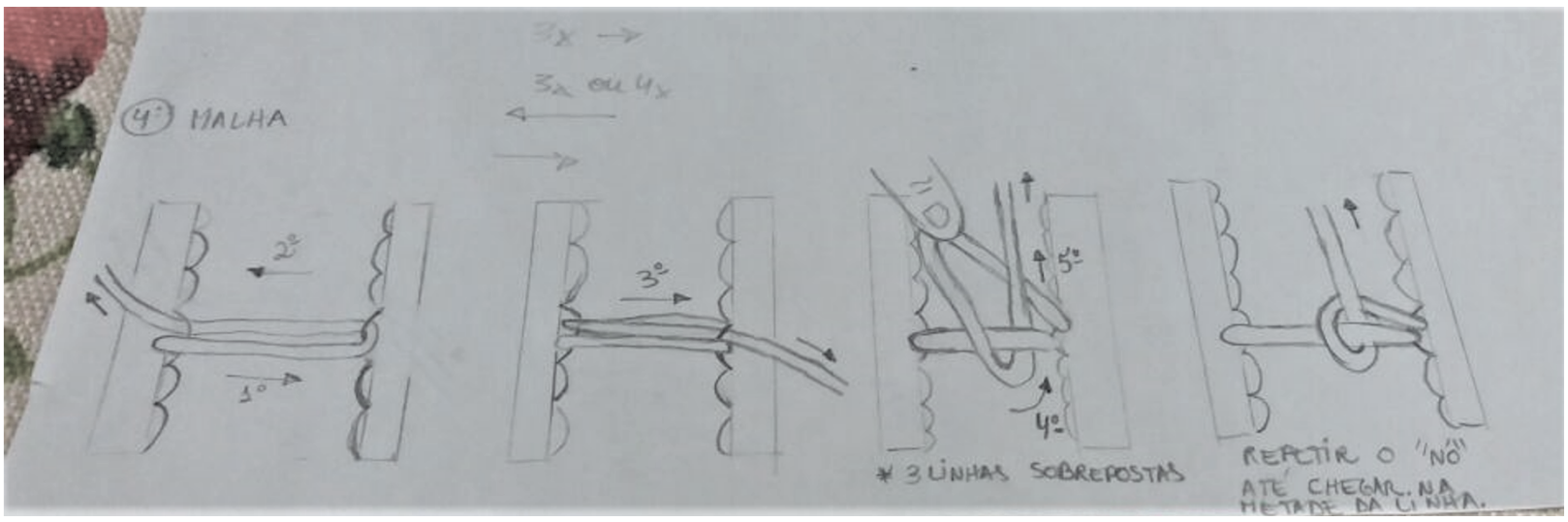

Após quatro dias de aprendizagem dos pontos no município de Poção, a pesquisadora testou a capacidade de elaboração dos pontos sozinha, em Recife, através dos desenhos trazidos na mala. Foi possível executar a feitura de todos, seguindo o passo a passo retratado nas imagens. Depois desta confirmação, os desenhos foram passados para o Adobe Illustrator, devido à precisão da tecnologia na repetição dos desenhos. Abaixo, na Figura 03, é possível observar o último estágio de teste que passaram os desenhos antes da sua reprodução computadorizada.

Figura 02.

Desenho à mão das trajetórias de linhas e agulha.

Fonte: Acervo da autora. 
Figura 03.

Confecção dos pontos pela pesquisadora, através da leitura dos desenhos.

Fonte: Acervo da autora.
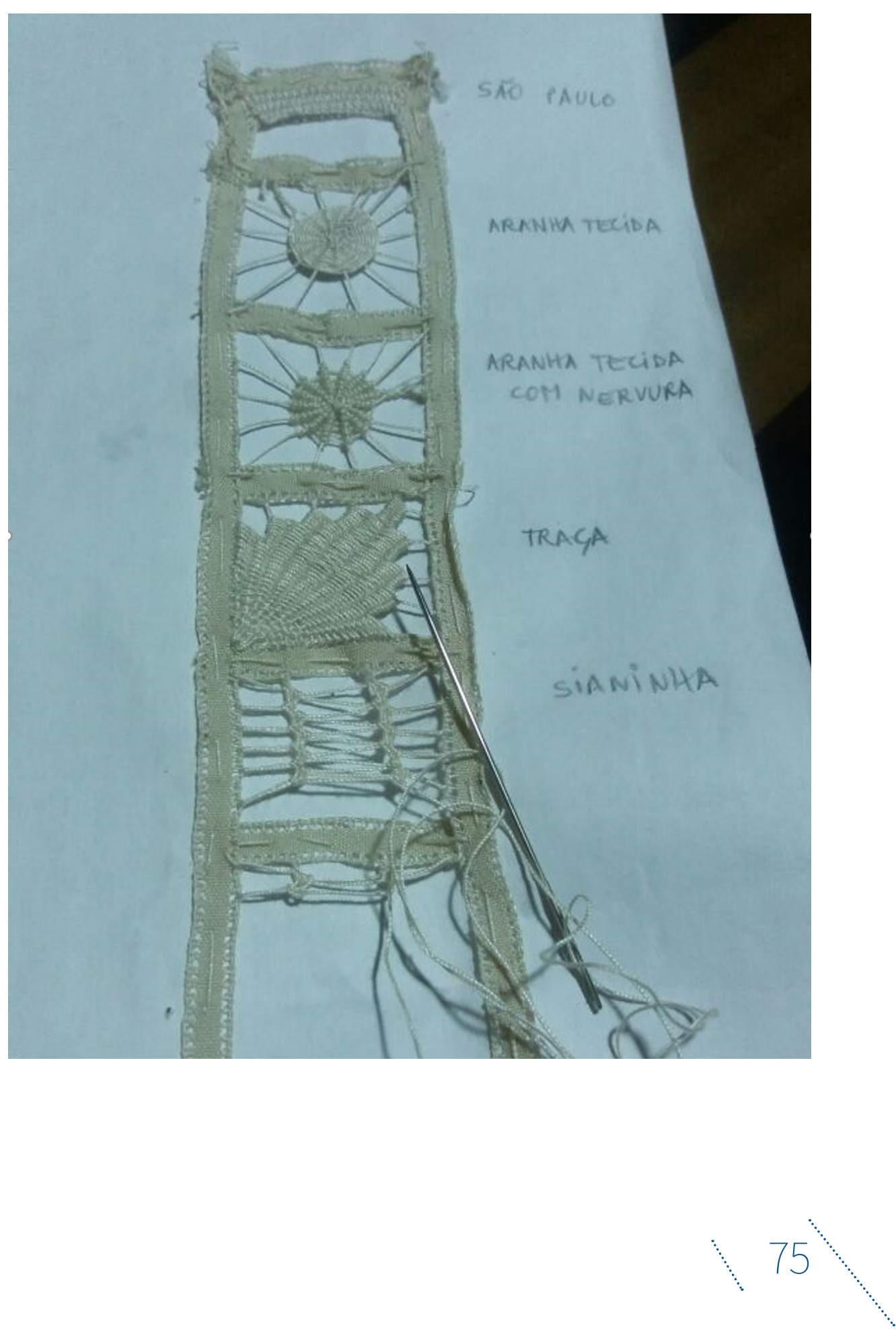


\section{DESIGN DA INFORMAÇÃO: REPRESENTAÇÃO DA AÇÃO}

Segundo Pettersson (2015), assim como a fala e a escrita, a linguagem visual tem a sua própria "gramática". Os arranjos espaciais dos elementos visuais em uma página são considerados a sintaxe visual e o sistema perceptivo humano determina a eficácia e eficiência da mensagem. Algumas ideias são melhor demonstradas pela linguagem visual, outras, só podem ser expressas desta forma, que é considerada uma poderosa maneira de comunicação por estimular tanto respostas intelectuais quanto emocionais ao mesmo tempo.

Comparada a um texto, uma figura propaga uma maior quantidade de informação. O ser humano seleciona e utiliza diferentes partes do conteúdo a cada visualização, por este motivo experimenta percepções distintas quando revê uma imagem em um novo contexto. A mensagem visual também proporciona maior liberdade de interpretação quando comparada à textual. Esta ambiguidade da imagem é um fator de preocupação para o Design, porque sempre haverá uma diferença entre a sua denotação, seu sentido literal, e 
sua conotação, os significados associados a ela. Já o campo das Artes Visuais, ao contrário, deseja que a figura seja capaz de gerar associações extras no pensamento dos leitores, e para tanto, utiliza-se de artimanhas como o exagero da perspectiva, a deformação da forma e a utilização da cor de maneira simbólica para estender ao máximo o potencial conotativo das imagens.

No caso das figuras construídas com o intuito de representar movimento, há uma peculiaridade: "a ação não é vista realmente, mas percebida como tal a partir do conteúdo, dos elementos gráficos da obra pictórica e da participação do leitor" (WANDERLEY, 2006, p.127). Cabe ao designer sugerir a ação, provocá-la da forma mais eficaz através de informações conceituais e gráficas. A conclusão do ato ocorre na mente do leitor, devido à capacidade humana de desenvolver imagens mentais a partir de tudo que é visto, ouvido e sentido, formando uma base imagética para a percepção - estas figuras são chamadas de "schematas".

Os "schematas" são desenvolvidos a partir das diferentes experiências e aprendizagens ao longo da vida. Portanto, nota-se que é de grande importância a participação do leitor no processo perceptivo da ação, visto que os repertórios mentais de imagens serão particulares, de acordo com a cultura, idade, interesses e vivências de cada leitor.

Wanderley (2006) desmembra as informações conceituais em cinco principais elementos: os participantes, os movimentos, a frequência, a trajetória e a velocidade. No caso específico do desenho dos pontos da Renda Renascença, foram identificados três participantes: a pessoa que vai tecer (o participante agente), a agulha (o participante objeto) e a 
linha/trama (o participante paciente). A ação de tecer é composta por vários movimentos e apresenta uma alta frequência - assim que um ponto é aprendido ele é repetido inúmeras vezes até o preenchimento total do espaço entre as bordas do lacê. A trajetória, as direções e os sentidos serão indicados pelas setas próximas à agulha. 0 elemento velocidade não é significativo para a representação esquemática do "fazer renda", visto que se trata de um desenho de "passo a passo", de ensino/aprendizagem, embora a Renascença seja tecida com bastante velocidade pelas rendeiras experientes.

$\mathrm{Na}$ comunicação visual, as informações gráficas expressam as informações conceituais vistas acima, portanto utilizar a quantidade certa de elementos gráficos e encontrar o equilíbrio visual da imagem são dois objetivos que devem ser perseguidos pelo designer na criação dos desenhos esquemáticos. As legendas também são outro ponto fundamental para guiar a compreensão do conteúdo nos materiais informativos e instrucionais, apontando para o caminho intencionado. Pettersson (2015) alerta para o fato que o excesso de informação gera uma imagem sobrecarregada, difícil de interpretar. Quando há muitos elementos visuais em uma só imagem, alguns pontos podem passar despercebidos pelo leitor e haverá menos espaço para o texto das legendas. Uma informação visual efetiva cria uma experiência: o público é capaz de notar a imagem, prestar atenção a ela, ler a figura de forma ativa e seletiva e processar a informação mentalmente. Os elementos básicos em uma figura são os pontos, as linhas e as áreas e as mais importantes variáveis visuais são: posicionamento, forma, direção, cor, 
densidade, granulação (ou textura) e tamanho. Quando as variáveis são usadas simultaneamente, a hierarquia da visibilidade é importante: os símbolos maiores são sempre percebidos primeiro, o tamanho é mais importante que a forma e a cor.

O designer deve usar a cor para enfatizar ou atenuar algum aspecto, mostrar diferenças ou similaridades e ajudar os leitores a lembrarem de algumas informações. Segundo Pettersson (2015), quando cores de igual intensidade são comparadas, os tons mais visíveis são o branco, o amarelo e o verde, nesta ordem. Os matizes menos visíveis são o vermelho, o azul e o violeta. Tons comumente empregados em símbolos gráficos são o amarelo, o vermelho, o azul, o verde, o branco e o preto, ou combinações deles. As cores também podem ser combinadas com a forma e a posição.

Os significados simbólicos de cada cor variam de cultura para cultura e Pettersson (2015) alerta aos designers para o cuidado com o uso das cores em materiais informativos internacionais. É sempre uma boa solução projetar imagens em preto e branco e, posteriormente, se necessário, adicionar cor para realçar alguns aspectos. De todas as formas, "a cor melhora a atenção e a percepção de uma mensagem visual. Se as pessoas gostam do conteúdo de uma imagem, elas gostam 
ainda mais quando é apresentado em cores" (Pettersson, 2015, p.203; tradução nossa). 0 destaque dado pela cor tende a tornar a imagem mais lembrada, pois é capaz de realçar a comunicação e adicionar clareza e impacto à imagem. Destacar, separar, definir e associar são ações frequentemente feitas através do uso da cor.

Souza (2008) conceitua quatro tipos de imagens instrucionais: as imagens compostas, que são arranjos lineares de um conjunto de figuras individuais, chamadas de imagens discretas ou sub-imagens; as imagens sinóticas, que são sumários visuais de uma série de operações e representam vários eventos, originados em diferentes tempos e espaços, em uma única figura; as imagens de antes, durante e depois da ação, que além de demostrarem o movimento, também detalham o antes e o depois, como o próprio nome já se auto explica; e as imagens únicas, que utilizam uma única figura para evocar todo o movimento e dependem da habilidade do leitor de imaginar toda a ação vendo apenas um recorte dela. Como os pontos da renda Renascença são tramas complexas e envolvem o cruzamento de muitas linhas, a imagem composta se mostrou a mais adequada para esquematizar a série de movimentos do "fazer renda". A maioria dos pontos foi demonstrada utilizando-se entre quatro e seis etapas, portanto, um arranjo linear horizontal, contendo quatro ou seis imagens discretas.

Spinillo (2001) traz à tona o conceito de sequências pictóricas de procedimentos (SPPs). Os produtos eletrônicos acompanhados de manuais de instrução, traduzidos em diversos idiomas devido à 
globalização, são o maior exemplo do uso das SPP nos dias atuais. Além dos manuais de suporte de produtos manufaturados, as SPPs são também bastante utilizados em literaturas de "passo a passo": livros de artesanato, de jardinagem, de culinária e de "Faça você mesmo" (DIY - Do it yourself) são exemplos deste tipo de publicação. $O$ uso das SPPs em materiais gráficos de campanhas de saúde e na educação como um todo demonstram também a importância social do seu uso.

As sequências pictóricas de procedimentos são uma narrativa, já que explicam a sequência de passos a ser seguida para a realização de uma tarefa, e devem gerar uma única maneira de interpretação. Relacionando os conceitos de Spinillo (2001) e Souza (2008), toda SPP é uma imagem composta, entretanto nem toda imagem composta é uma SPP, já que nem todos os arranjos lineares de figuras tratam da explicação de procedimentos. As representações artificiais do movimento podem ser estáticas (ilustrações, fotografias, gráficos) ou dinâmicas (animações), neste trabalho foi escolhida 
a representação estática, por desenhos, seguindo uma sequência horizontal, com uma orientação explícita.

Souza e Lima (2010) demonstram como recursos gráficos podem aumentar a clareza de imagens que representam instantes de movimentos, como é o caso das figuras do passo a passo da confecção dos pontos da renda Renascença. A seta é o recurso de maior popularidade nos esquemas imagéticos. Além de apontar a direção, sua ponta indica o destino do movimento e sua "cauda", a origem. $\mathrm{O}$ tamanho, a textura e a forma da haste esquematizam a trajetória do deslocamento: ziguezague, circular, curva, reta, etc. Nos materiais informativos, as setas são equivalentes a verbos de movimento: girar, levantar, empurrar, seguir, etc. Para os desenhos das etapas do trabalho artesanal têxtil, elas guiam os variados caminhos da agulha e servem para indicar a direção das carreiras dos pontos tecidos.

Thérèse de Dillmont (1920), austríaca que viveu na última metade do século XIX, escritora e especialista em trabalhos manuais com agulhas, deixou um amplo legado de livros sobre $o$ artesanato têxtil europeu. Interessante notar que ainda há uma grande semelhança entre a renda produzida na
Europa nos finais do século XIX e a confeccionada no interior de Pernambuco nos dias atuais. Estruturas e pontos foram mantidos ao longo de quase um século e meio pela força da tradição. Dillmont (1920) foi a maior referência, para esta pesquisa, na representação gráfica do movimento da agulha, dos nós e dos caminhos das linhas. Ela deixou um vasto trabalho, fundamental para a preservação da memória da produção de rendas no mundo.

Ao observar os livros de padrões existentes, nota-se que a familiaridade com a ação de tecer influencia na compreensão dos desenhos esquemáticos dos pontos. Uma pessoa que nunca teve contato com técnicas de costura terá um repertório de imagens mentais relacionadas ao tema menor do que o de uma costureira, por exemplo. A experiência com o conteúdo da mensagem reflete na interpretação da ação representada. Wanderley (2006) afirma que, embora as pesquisas sobre a participação do leitor no processo comunicativo necessitem de atualização, é possível concluir que elementos como idade, escolaridade e cultura do leitor influenciam na forma de interpretar o movimento comunicado pela figura. 
Figura 04.

Apresentação dos

símbolos criados.

Fonte: Elaborada

pela autora.

\section{REPRESENTAÇÃO GRÁFICA DOS PONTOS}

A lista de pontos dividida em quatro "famílias", organizada em uma ordem crescente de complexidade, mostrou-se uma forma didática para a apresentação e ensino dos pontos. A compreensão do primeiro ponto de cada "família" torna mais fácil a elaboração dos seguintes, ainda que apresentem um maior grau de dificuldade, porque todos estão alinhados em uma mesma lógica de construção têxtil. Antes de apresentar as imagens de representação dos pontos, é necessário explicar os símbolos criados, conforme Figura 04, abaixo:

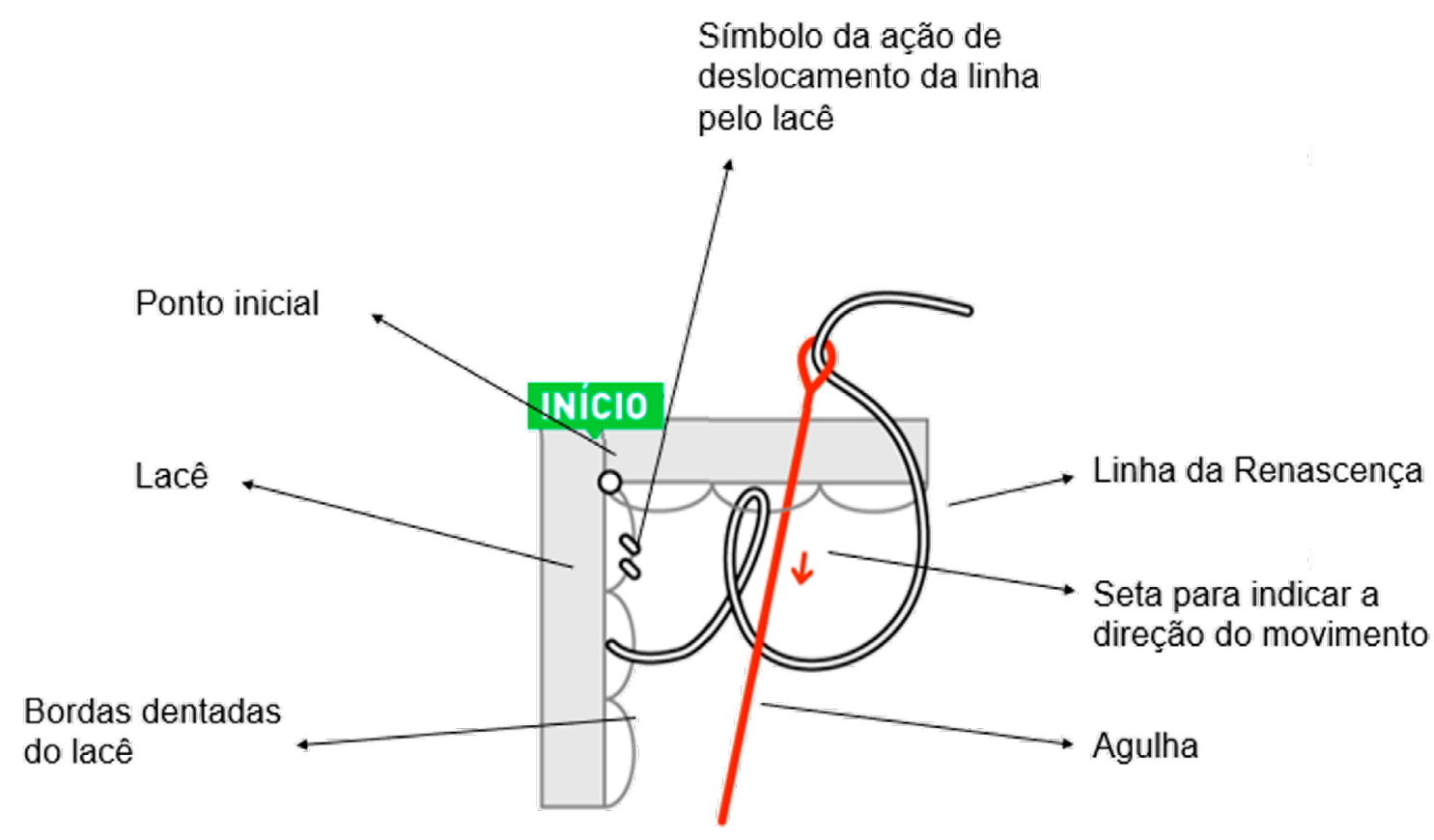


Os retângulos longos na cor cinza claro representam o lacê; as linhas cor cinza claro representam a borda dentada do lacê (foram desenhadas apenas as bordas internas do lacê, que dão sustentação aos pontos a serem apresentados - eliminamos as bordas externas do lacê do desenho para evitar o excesso de informação na figura); a agulha foi desenhada na cor vermelha, para chamar atenção ao instrumento que dita o caminho da linha e visto que o vermelho tende a ser percebido como um tom ativo/agressivo; a linha branca com as bordas pretas é a linha de algodão da Renascença, ela foi desenhada desta forma porque as linhas de contorno na cor preta permitem o entendimento da sobreposição de nós e da própria linha; a pequena bola branca com contorno de linha preta representa o ponto de costura inicial que dá início ao trabalho, está sempre acompanhada da palavra "Início", na cor verde, escolhida por ser a cor complementar da cor vermelha (cor da agulha) e apresentarem maior contraste entre si; as setas vermelhas indicam o sentido do movimento da agulha e/ou das linhas.

Para demonstrar o que foi realizado nesta pesquisa, devido às contigências editoriais, apresentaremos os desenhos esquemáticas de dois importantes pontos da renda Renascença, o "Dois Amarrado" e o "Pauzinho": 


\section{"DOIS AMARRADO"}

Ponto base para a confecção da renda Renascença, o conhecimento do "Dois amarrado" é imprescindível para quem deseja adentrar neste universo, porque é um ponto amplamente utilizado para a cobertura de grandes áreas do trabalho têxtil, assim como do qual derivam muitos outros pontos. Abaixo, na Figura 05, é possível observar o passo a passo para sua elaboração. 0 nome deste ponto resume a sua execução: são duas alças amarradas, daí o "Dois amarrado".

1

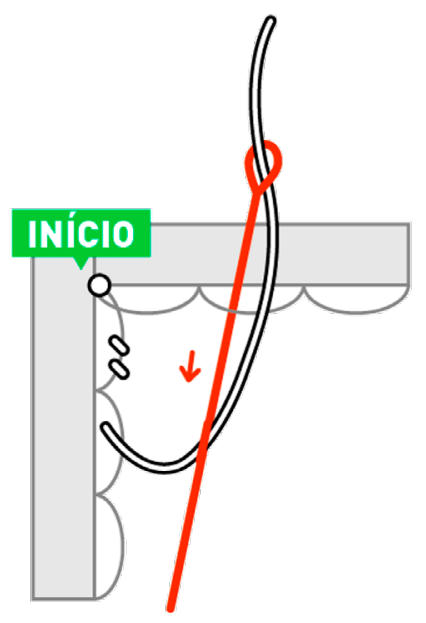

Figura 05.

Passo a passo do

"Dois amarrado", da esquerda para a direta.

Fonte: Elaborada pela autora.

3
2
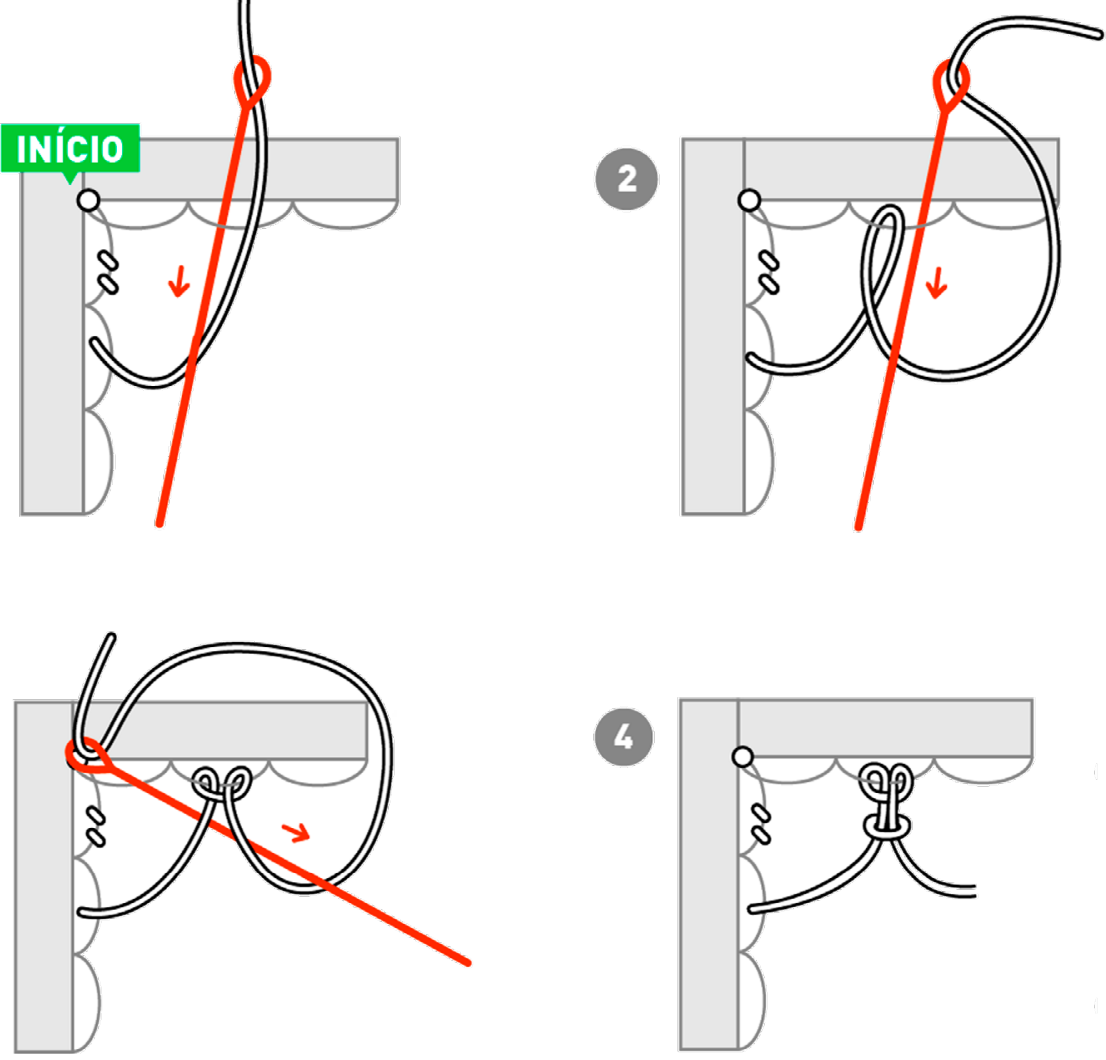

4

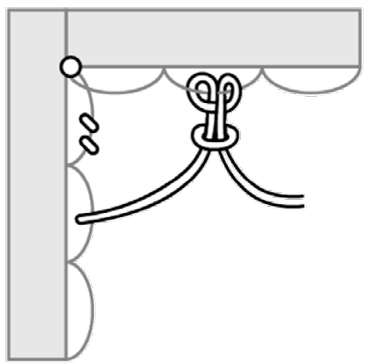


Inicia-se com um ponto de costura simples emendando às bordas do lacê, desliza-se a linha um pouco para baixo, pelo lacê, e com três movimentos de agulha conclui-se o ponto. Foi retratada a construção do ponto da esquerda para a direta. Quando a carreira começa da direta para a esquerda, o ponto é apenas espelhado, linhas e agulha invertem de lugar (em caso de dúvida, posicionar um espelho do lado esquerdo dos desenhos). $\mathrm{Na}$ Figura 06, abaixo, é possível observar a visão final de quatro carreiras de pontos: a primeira e a terceira foram tecidas da esquerda para direta e a segunda e a quarta foram tecidas da direta para a esquerda (as setas vermelhas indicam o sentido a direção de construção dos pontos). Na Figura 07, é possível observar o preenchimento com "Dois amarrado" em uma parte da renda.
Figura 06.

Visão final de quatro carreiras de "Dois amarrado".

Fonte: Elaborada pela autora.

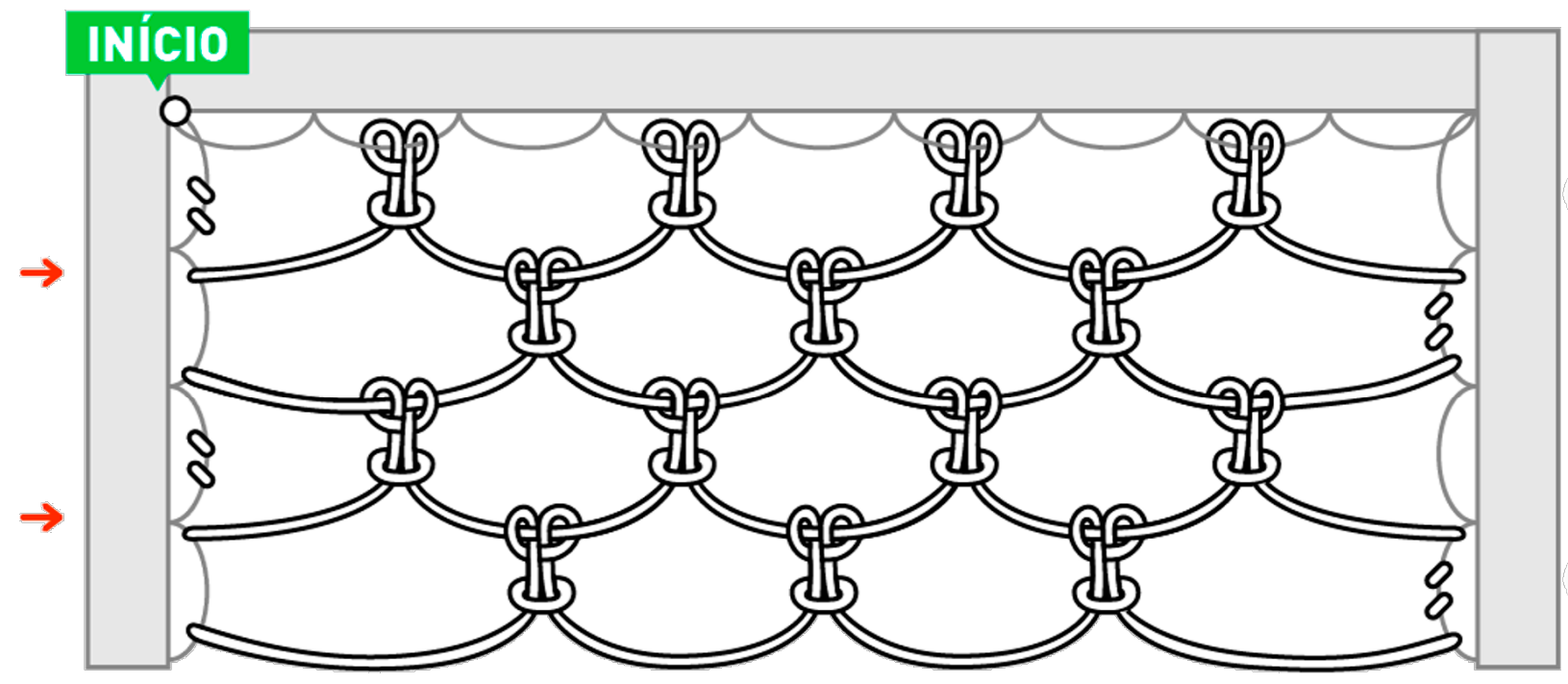


Figura 07.

Ponto "Dois amarrado"

aplicado na Renascença.

Fonte: Acervo da autora.

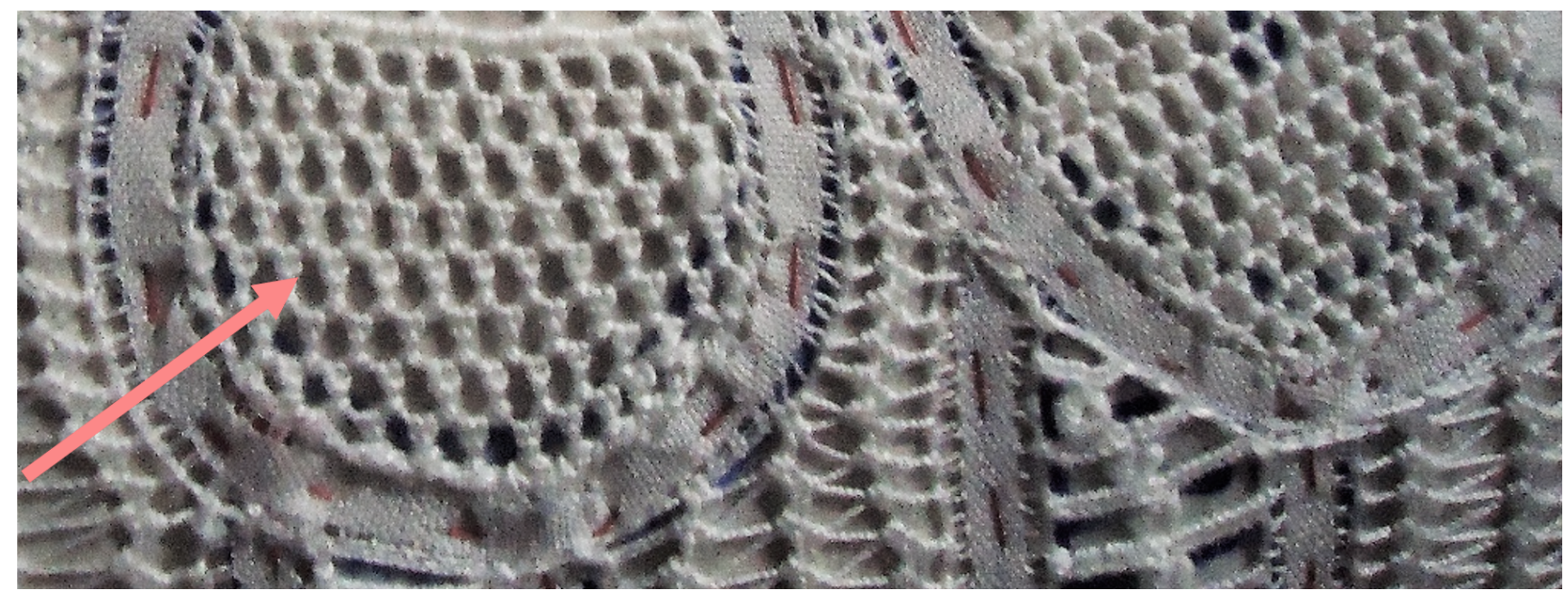

A partir do aprendizado deste ponto, é possível aprender outros seis, que derivam, de certa forma, dessa estrutura inicial, sendo eles: "Torre", "Abacaxi”, "Abacaxi de dois", "Abacaxi de três", "Amor seguro" e "Xerém".

\section{"PAUZINHO"}

O ponto "Pauzinho", também conhecido pelo nome de "Richelieu", é utilizado para preenchimento de espaços estreitos da renda. Para inicia-lo é necessário passar a linha três vezes na horizontal, como é possível observar no primeiro e segundo passos da Figura 08, e posteriormente o "Pauzinho" é tecido "encapando" os três fios iniciais, como é possível observar no terceiro e quarto passos, abaixo. Na Figura 09 pode-se ver o ponto tecido, compondo a Renascença. 

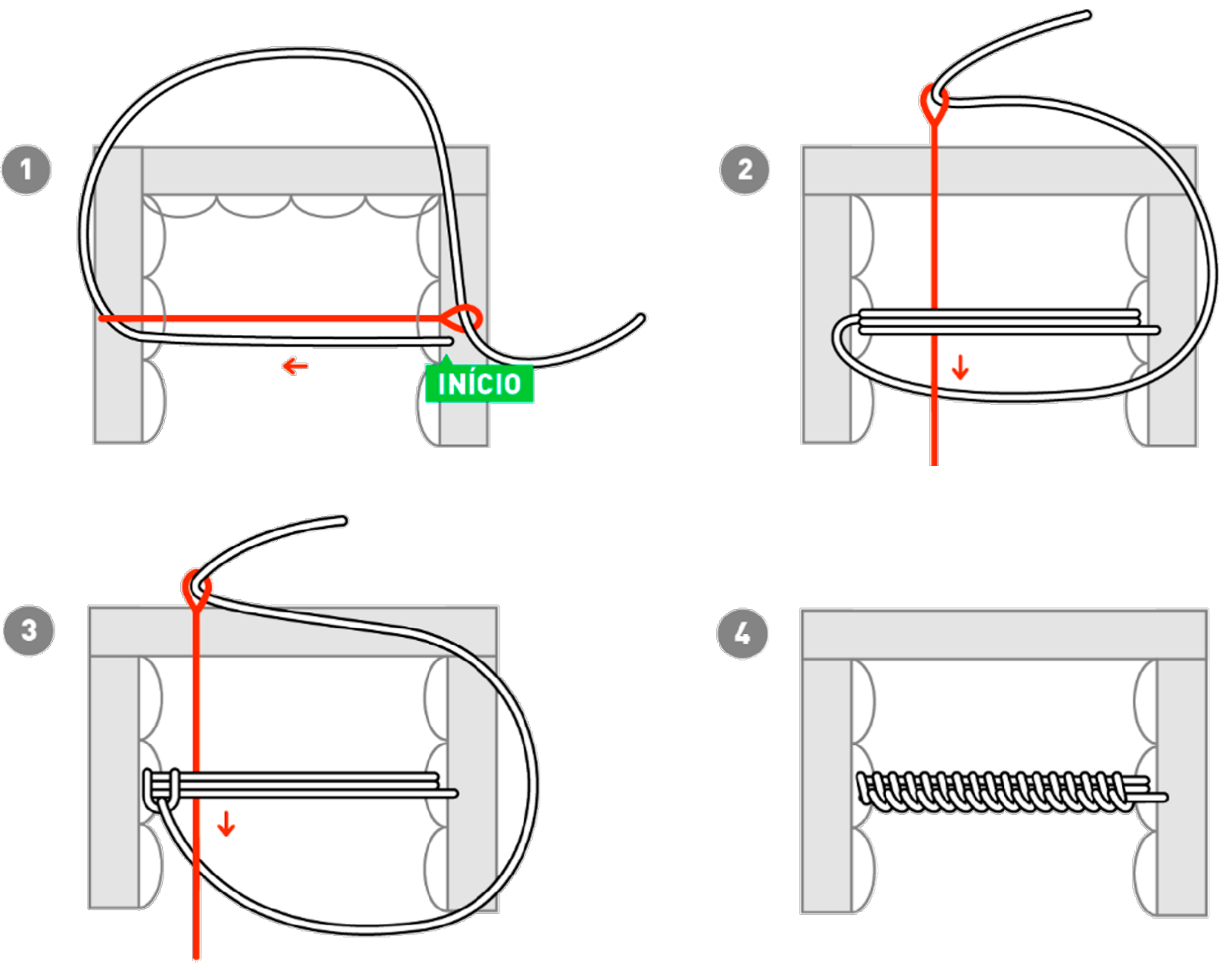

4

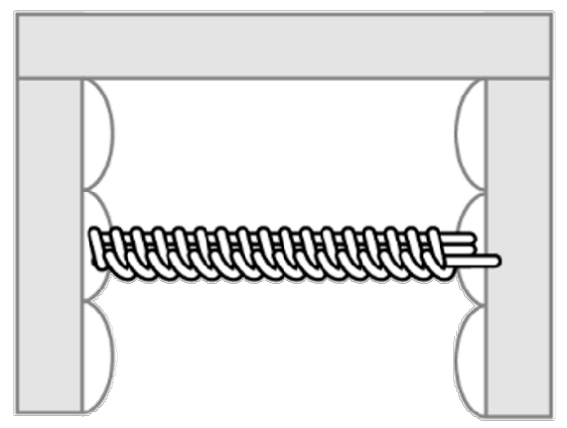

Figura 08.

Passo a passo do ponto "Pauzinho". Fonte: Elaborada pela autora. 


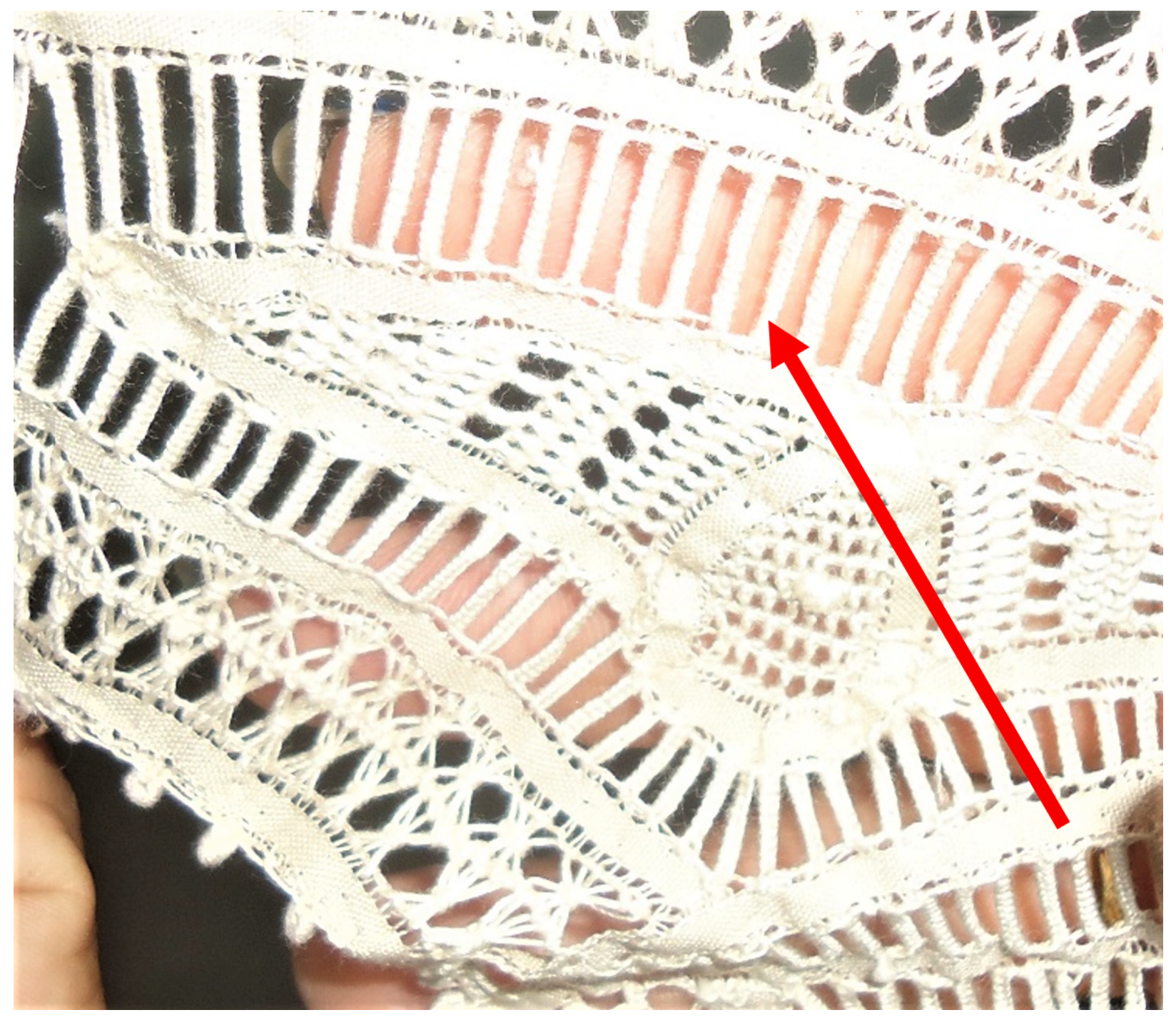

A partir do aprendizado deste ponto, é possível aprender outros três, que derivam, de certa forma, dessa estrutura inicial, sendo eles: "São Paulo", "Pipoca" e "Malha".

Figura 09.

Ponto "Pauzinho"

aplicado na Renascença.

Fonte: Acervo da autora. 


\section{CONSIDERAÇÕES FINAIS}

Estas representações imagéticas contribuem para enriquecer a memória da produção têxtil artesanal do país. Ao todo, foram retratados, em desenhos esquemáticos, dezesseis pontos da Renascença: "Dois amarrado", "Torre", "Abacaxi", "Abacaxi de dois", "Abacaxi de três”, "Amor seguro", "Xerém", "Pauzinho", "São Paulo", "Pipoca”, "Malha", "Aranha tecida", "Aranha tecida com nervura", "Traça", "Sianinha" e "Sianinha de laço". No entanto, aqui, só foi possível apresentar dois deles.

Futuros estudos complementares a este podem investigar a criação de uma etiqueta de produto que ressalte as características diferenciadoras contidas em cada peça, como: a quantidade e a complexidade dos pontos envolvidos, a qualidade das matérias primas empregadas, a quantidade de pessoas envolvidas na execução e o tempo levado para finalização do trabalho manual. Instruir o consumidor o torna capaz de perceber o real valor do produto artesanal, sobretudo quando se trata da Renascença, já que o tempo de produção deveria ser o principal componente do preço da mercadoria.
A partir dos registros visuais gerados também é possível o desenvolvimento de um estudo comparativo entre as construções têxteis da renda Renascença produzida na Europa, no final do século XIX e início do século $X X$, encontrada no livro de Dillmont (1920) e a da renda Renascença produzida no Brasil, no início do século XXI, ou seja, quase 100 anos depois. Este campo de estudo fica disponível para futuras investigações.

Uma limitação da pesquisa foi a ausência da medição da capacidade de confecção dos pontos por pessoas que nunca tiveram contato com a técnica têxtil da Renascença, a partir apenas da compreensão dos desenhos esquemáticos. Esta comprovação, assim como futuras análises sobre a eficiência do passo a passo poderão ser tratadas em artigos de desdobramento desta pesquisa.

Para o campo de Design, este estudo contribui para enriquecer o acervo da história do design artesanal têxtil brasileiro, especialmente com a criação da representação gráfica do movimento das linhas e agulhas dos pontos da Renascença, tornando possível o resgate da técnica a qualquer tempo, caso esta venha a se perder com o passar dos anos. 


\section{REFERÊNCIAS}

\section{DILLMONT, T. La Dentelle Renaissance.}

Mulhouse: Mulhouse (Alsace), 1920.

MARCONI, M. A.; LAKATOS, E. M.

Fundamentos de metodologia científica.

5ed. São Paulo: Atlas, 2003.

NÓBREGA, C. Renda renascença: Uma memória de ofício paraibana. João Pessoa: SEBRAE, 2005.

PETTERSSON, R. Image Design. Viena: IIID Public Library, 2015.

Pontos e histórias: Renda Renascença e Mulheres Rendeiras. / Fundo Internacional de Desenvolvimento Agrícola, Instituto Interamericano de Cooperação para a Agricultura, Agência Espanhola de Cooperação Internacional. - Salvador: IICA, 2017

QUEIROGA, L. Lagarta Richelieu. Recife: Lenice Queiroga de Sousa, 2013.

Renascença - PE. / Governo de Pernambuco. - Recife: Cel Editora, 2016.

SOUZA, J. M. B. Towards the optimization of software instructional demonstrations: the effects of visual representations of operational information and interaction on users' performance and judgments. 2008. 227 p. Tese (Pós-doutorado em Tipografia e Comunicação Gráfica) - University of Reading, Reading, 2008.

SOUZA, J. M. B.; LIMA, R. C. O design de gráficos auxiliares na representação de movimento para fins instrucionais. In: $9^{\circ}$ Congresso Brasileiro de Pesquisa e Desenvolvimento em Design. 2010.

SPINILLO, C. G. Ananalytical approach to procedural pictorial sequences. 2001. 234 p. Tese (Doutorado em Tipografia e Comunicação Gráfica) - Universityof Reading, Reading, 2001.

WANDERLEY, R. G. Uma Abordagem para a Representação Gráfica de 'Ações Dinâmicas'. 2006. Dissertação (Mestrado em Design) - Departamento de Design, Universidade Federal de Pernambuco, Recife. 